\title{
ANALYSIS OF DIFFERENT PROBE-LABELING SYSTEMS FOR DETECTION BY HYBRIDIZATION OF BOVINE CORONAVIRUS
}

\author{
J.A. Verbeek, S. Dea, and P. Tijssen \\ CRMC - Institute Armand-Frappier - University of Quebec \\ Laval-des-Rapides, Quebec, Canada, H7N 4 Z3
}

\section{INTRODUCTION}

Several methods for the detection of bovine coronavirus (BCV) in clinical specimens have been developed (1-5). The notoriously difficult diagnosis by EM has recently been improved by the use of immunogold (3), whereas other methods have been described, based on serological detection $(2,5)$ or on the hemagglutinating capacity of the virus $(6,7)$. Even though increased specificity in immunological detection assays can be obtained using monoclonal antibodies, sensitivity and detectability still remain to be improved.

It has been shown that cDNA probes can be applied to detect viral RNA, isolated from tissue culture-propagated virus (8), whereas in a subsequent study (9), conditions were optimized for BCV detection without previous RNA isolation. Purified virus was directly applied in low-salt concentrations to the nitrocellulose membrane and denaturation and RNA fixation was conveniently achieved by baking the blots under vacuum.

In this report, we discuss different probe-labeling systems for BCV detection by hybridization. Furthermore, data are provided on the adaptation of this test system for clinical sample processing and virus detection, and for virus-specific sequence amplification by the polymerase-chain-reaction (PCR).

\section{MATERIALS AND METHODS}

\section{Virus and cells}

The NCDC strain (Mebus) of BCV was obtained from the American Type Culture Collection and propagated in human rectal tumor (HRT-18) cells (10). Virus purification was as in previously described methods (11).

\section{$\underline{\text { Probes }}$}

Recombinant plasmids (vectors) used in probing assays, were selected from genomic-cDNA libraries, obtained by cloning oligo-dT or random primed-cDNA (9) or by cloning of polymerase-chain-reaction (PCR) amplified BCV-specific fragments.

Probe selection was based on the capacity of clones to hybridize strongly in colony-filter hybridization assays (12). Two other vectors, containing inserts, representing the translational reading frames for the nucleocapsid $(\mathrm{N})$ and the matrix (E1) protein, as shown by sequence analysis, were also chosen as they have already been characterized (13). 
Vectors were purified on $\mathrm{CsCl}$ gradients and their corresponding cDNA inserts were obtained by electro-elution, after separation of the restrictionenzyme digested DNA on an agarose gel.

\section{Probe-labeling}

Vectors or purified cDNA inserts were labeled by nick-traznslation (14) or random priming (15) in the presence of radioactive precursors $\alpha^{32} \mathrm{P}$ dCTP, 3000 $\mathrm{Ci} / \mathrm{mmol}$ ). Biotinylated probes were obtained as described by Leary et al (16).

PCR-synthesized probes were principally labeled as described by Schowalter et al. (17), using as template, a vector that contained the $3^{\prime}$ end of the genome until position 817 (13). Primers used in the amplification system were 5' GGC TCT ACT GGA TGC GCG TGA AGT AGA TCT GG and 5' ATG TCT TTT ACT CCT GGT AAG CAA, respectively, to amplify a $624 \mathrm{bp}$ fragment. The synthesis of radio-isotopically labeled single-stranded (ss) probes by PCR, was done by incubation of the same, but linearized vectors with an RNA complementary primer, resulting in a linear rather than exponential amplification without any plasmid sequences. All labeled probes were separated from non-incorporated radionucleotides by spun-column chromatography, using Sephadex-G50.

\section{Hybridization}

Hybridization was done under optimized conditions (9) for 2 days at $42^{\circ} \mathrm{C}$. Washing of the blots was done according to standard procedures (12) and autoradiograms were exposed at $-70^{\circ} \mathrm{C}$ overnight, using intensifying screens.

\section{Sample application and processing}

Serially-diluted purified virus was spotted on nitrocellulose membranes in final concentrations of 1xSSC (9), by means of a slot-blot apparatus (Schleicher and Schuell Inc.). Ten times diluted clinical specimens were directly applied to the membrane or after extraction with either of the following organical solvents; (phenol/chloroform (1:1), Freon (1,1,2 trichloro-1,2,2,-trifluorethane), carbon tetrachloride or chloroform).

Viral RNA, used for CDNA synthesis and PCR amplification (18), was isolated from clinical specimens by means of acid guanidium thiocyanate-phenolchloroform (19).

Selective virus capture methods for detection by hybridization are discussed in the Results and Discussion section.

\section{RESULTS AND DISCUSSION}

\section{BCV detection by nick-translated probes}

Several CDNA inserts, varying in size fom 0.6 to $2.0 \mathrm{~kb}$, and their corresponding vectors were labeled with radio-isotopes by nick-translation and independently used to detect serial dilutions of purified virus (one example is given in Fig. 1). Although probe inserts yielded specificities, sensitivities and detectabilities were reduced 5 to 8 times, respectively (Fig. 1). Two hours exposure of the autoradiograms to the blots showed detection signals obtained by vector probing that equalled those obtained by insert probing after a $24 \mathrm{~h}$ exposure time. Larger size insert-probes gave slightly better results than smaller ones. When using a pool of three non-overlapping insert-probes in the same hybridization assay, sensitivity and detectability levels still did not reach those obtained by probing with one single, radiolabeled vector. However, detectability and sensitivity was increased 14 and 6 times respectively, when using a probe-pool of 6 vectors containing non-overlapping CDNA sequences, thus hybridizing to different locations on the genome. These data demonstrate the significance for detection by hybridization of labeled plasmid fragments, attached to the cDNAprobe sequences involved in target hybridization. The formation of hyperpolymers 


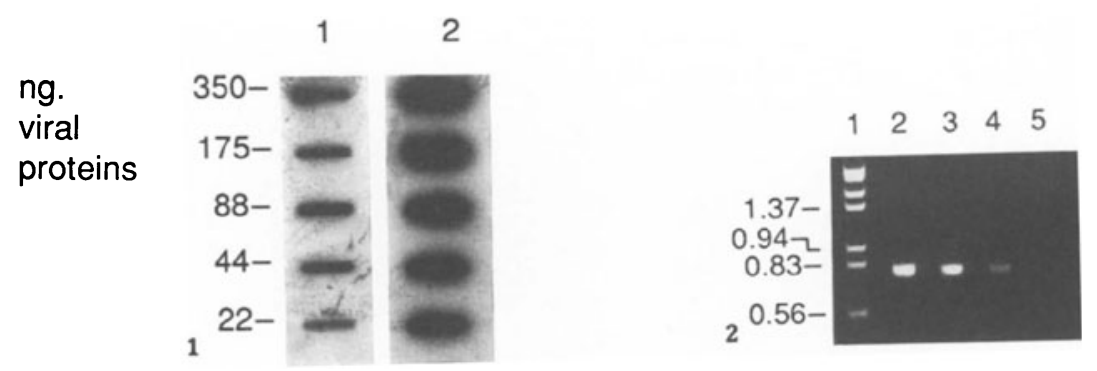

Fig. 1 Detection by hybridization of BCV with a nick-translated CDNA insert

(600 bp; lane 1) or its corresponding vector (lane 2).
An amount of $100 \mathrm{pg}$ viral protein correspond to about $1.1 \times 10^{5}$ virus particles and about 1.1 pg genomic RNA.

Fig. 2 Agarose-gel electrophoresis of BCV-specific fragments, amplified by PCR, using isolated genomic RNA as template. ${ }^{\text {Amounts }}$ of ${ }_{2}$ RNAmolecules used in the amplification systems were $10^{3}$ (lane 2), $10^{2}$ (lane 3), 10 (lane 4) and 1 molecule, respectively. One tenth of the PCR reaction volume was analyzed. Lane 1 , DNA markers.

by vector sequences on the target sites likely plays a role in detection signal amplification. It was already established in previous studies (9) that pUC-9 sequences did not cause background signals, thus ensuring the specificity of the signals obtained.

\section{$\underline{\text { Random-primed probes }}$}

Probes, labeled by random priming showed superior sensitivities and at least 7 times increased detectabilities than corresponding nick-translated probes, but at the same time, background signals were similarly increased, resulting in a more difficult determination of the detection-limit.

Background signals, likely due to non-specific probe trapping, and strongly amplified detection signals of spotted plasmid DNA, might lead to misinterpretation and an increased score of false-positive identifications, when probing clinical specimens, although this was not further investigated.

\section{Biotinylated probes}

Biotinylated probes (16) were shown to be superior for detection of BCVRNA, isolated from purified virions (9). About $3 \times 10^{3}$ particles could be detected using amplification systems (9). However, probing of clinical specimens with these probes resulted in strong background hybridization signals, thus increasing the score of false-positive identifications significantly.

Incubation of blots, on which fecal specimens were spotted, with biotinanalogs alone, was already sufficient to reveal strong detection-signals, indicating the uselessness of these probes, when samples were spotted directly onto nitrocellulose membranes without previous RNA extractions.

\section{Probes synthesized by PCR}

Double-stranded probes, synthesized in an exponential amplification system 


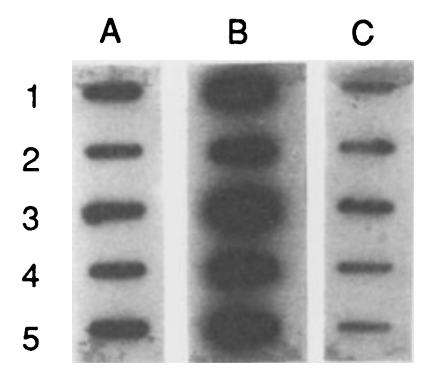

Fig. 3. Detection of $\mathrm{BCV}$ in 5 clinical specimens (nrs 1-5) with a probe-pool, consisting of 6 radiolabeled vectors (lane A) or with a PCR-synthesized single-stranded probe (lane B).

Detection signals of the PCR amplified products synthesized on viral RNA, isolated from the clinical specimens, are shown in lane C.

$\left((1+a)^{n} ; a=\right.$ efficiency of PCR, $n=$ number of cycles), gave 2 to 3 times increased sensitivities and at least 15 times higher detectabilities. However, background signals were very high, even after only $8 \mathrm{~h}$ exposure time. An exposure time of two hours did not result in background development and in this case detectabilities equalled those obtained by nick-translated probes, after a $24 \mathrm{~h}$ exposure period.

PCR, performed on the same, but linearized vector ternplate, and in the presence of only the RNA complementary primer, resulting in a linear amplification $(n(1+a))$ of radio-isotopically-labeled single stranded probes, resulted in strongly improved sensitivities and detectabilities. These probes were directly added to the prehybridization solution, without any previous denaturation. No background signals were seen even after overnight exposure of the autoradiograms.

Determination of the detection limit after amplification by PCR

Isolated viral RNA was serially diluted in DCEP treated water.

Four dilutions, approximately containing 1 to $10^{3}$ genomic-RNA molecules respectively, were processed for CDNA synthesis and PCR amplification of an 810 bp fragment, representing the translational reading frame of $E 1$ and a part of the $\mathrm{N}$-gene. CDNA synthesis was done by use of the RNA-complement primer (5' GAA CAT TTC TAG ATT GGT CGG ACT G ) annealing at position 925 to 901 (13), followed by PCR after the addition of the upstream RNA-sense primer (5' ATG AGT AGT GTA ACT ACA CCA GCA ) from position 115 to 138.

About 10 RNA genomes could be detected after agarose-gel electrophoresis of the amplified products (Fig. 2). The PCR products, except the one obtained from the highest dilution, could also be detected by hybridization with a nicktranslated probe. Isolated RNA, resuspended in DCEP treated water and stored for several month at $-20^{\circ} \mathrm{C}$, was still usable for amplification purposes.

\section{Application of molecular probes for BCV-detection in clinical specimens}

Detection by hybridization of $B C V$ in clinical specimens required several adaptations. Addition of purified virus to different BCV-negative clinical specimens, diluted 1:10 in TBS, resulted in strong variation of detection signals due to competition for binding sites on the membrane between the virus and other extraneous molecules. Several approaches were envisaged to either selectively 
capture the virus from specimens, or to eliminate macromolecules by extraction with organic solvents. Virus capture, by incubation of samples with rat red blood cells $(7)$ or by protein-A immunobeads, coated with polyclonal or monoclonal antibodies, was feasible but the amounts of virus captured or released were relatively poor for detection by hybridization. Similarly, captures were assayed by incubation of samples on immunoblots (i.e. blots coated with different dilutions of polyclonal or monoclonal antisera or with $\left(\mathrm{NH}_{4}\right)_{2} \mathrm{SO}_{4}$ concentrated immunoglobulins).

Although immunoblot-captures were better than the other methods described above, simpler extractions of the samples with organic solvents were superior with respect to the detection signals obtained. Among the organic solvents tested, Freon appeared to be the most adequate concerning macromolecule elimination and nucleocapsid preservation. BCV detection in Freon extracted samples with a probe-pool of 6 vectors, containing non-overlapping sequences, resulted in an increased sensitivity and test accuracy of $17 \%$ and $15 \%$ respectively, compared to data obtained by indirect ELISA. The use of PCR synthesized probes, either single or double stranded, for detection of the virus in clinical specimens also significantly improved the sensitivity and detectability, when compared to corresponding nick-translated probes. The detection signals obtained by probing $5 \mathrm{BCV}$-positive clinical specimens with the pool of vector probes (Fig. 3, lane A) and the hybridization signals, revealed after probing with a single-stranded probe, synthesized by PCR (Fig. 3, lane B) are shown in Fig. 3. Incubation of blots, on which clinical samples were spotted, with nick-translated radiolabeled pUC-19 sequences did not cause background hybridization.

Detection by hybridization of PCR-amplified products, synthesized on genomic-RNA templates, isolated from clinical specimens

Viral-RNA was isolated from five clinical specimens that were identified previously as positive. PCR was performed during 30 cycles using primers, described as above. Analysis by agarose-gel electrophoresis was not sufficient to visualize the amplified products. Detection by hybridization with a nicktranslated probe, however, showed that amplification had occured in all the samples analysed (Fig. 3, lane C). RNA, isolated from the specimens and which was 50 times more concentrated than the fraction used in the PCR amplification, was not detected. Although the probe used for detection was viral specific, radiolabeling of the amplified fragment(s) followed by size analysis would reveal the specificity of amplification. Studies are currently underway for application of $\mathrm{PCR}$ as a sensitive tool for clinical diagnosis of BCV.

Acknow ledgements

P. Tijssen acknowledges the financial support for this project from CORPAQ. A. Verbeek acknowledges support from WUSC.

These studies will be submitted as a part of a PhD thesis.

\section{$\underline{\text { References }}$}

1. Barnett, B.B., R.S. Splendlove, M.W. Peterson, L. Y. Hsu, V.A. La Salle, and L.N. Egbert. 1975. Immunofluorescent cell assay of neonatal calf diarrhea virus. Can. J. Comp. Med. 39:462-465.

2. Crouch, C.F., T.J.G. Raybould, and S.D. Acres. 1984. Monoclonal antibody capture enzyme-linked immunosorbent assay for detection of bovine enteric coronavirus. J. Clin. Microbiol. 19:388-393.

3. El-Ghorr, A.A., D.R. Snodgrass, and F.M.M. Scott. 1988. Evaluation of an immunogold electron micorscopy technique for detecting bovine coronavirus. J. Virol. Meth. 19:215-224. 
4. Flewett, T.H. 1978. Electron microscopy in the diagnosis of infectious diarrhea. J. Am. Vet. Med. Ass. 173:538-543.

5. Reynolds, D.J., D. Chasey, A.C. Scott, and J.C. Bridger. 1984. Evaluation of ELISA and electron microscopy for the detection of coronavirus and rotavirus in bovine faeces. Vet. Rec. 114:397-401.

6. Sato, K., Y. Inaba, S. Tokuhisa, Y. Miura, N. Kanedo, M. Asagy, and M. Matumoto. 1984. Detection of bovine coronavirus in feces by reversed passive hemagglutination. Arch. Virol. 80:23-31.

7. Van Balken, J.A.M., P.W. de Leeuw, D.J. Ellens, and P.J. Straver, 1978/79. Detection of coronavirus in calf faeces with haemadsorption-elutionhaemagglutinating assay (HEHA). Vet. Microbiol. 3:205-211.

8. Shockley, L.J., P.A. Kapke, W. Lapps., D.A. Brian, L.N.D. Potgieter, and R. Woods. 1987. Diagnosis of porcine and bovine enteric coronavirus infections using cloned cDNA probes. J. Clin. Microbiol. 25:1591-1596.

9. Verbeek, A., and P. Tijssen. 1988. Biotinylated and radioactive cDNA probes in the detection by hybridization of bovine enteric coronavirus. Mol. and Cell. Probes 2:209-223.

10. Laporte, J.P., P. Bobulesco, and F. Rossi. 1980. Une lignée cellulaire particulièrement sensible à la réplication du coronavirus entérique bovin: Les cellules HRT 18. Comptes Rendus Acad. Sc. (Paris). 290:623-626.

11. Dea, S., R. Roy, and M.E. Begin. 1980. Physicochemical and biological properties of neonatal calf diarrhea coronaviruses isolated in Quebec and comparison with the Nebraska calf corona virus. Am. J. Vet. Res. 41:23-29.

12. Maniatis, T., E.F. Fritsch, and J. Sambrook. 1982. Molecular cloning: a Laboratory Manual: Cold Spring Harbor, New York: Cold Spring Harbor Laboratory.

13. Lapps W., B.G. Hogue, and D.A. Brian. 1987. Sequence analysis of bovine coronavirus nucleocapsid and matrix protein. Virol. 157:47-57.

14. Rigby, P.W.J., M. Dieckmann, C. Rhodes, and P. Berg. 1977. Labeling deoxyribonucleic acid to high specific activity in vitro by nick translation with DNA polymerase I. $\underline{\text { J }}$ Mol. Biol. 113:237-251.

15. Feinberg, A.P., and B. Vogelstein. 1983. A technique for radiolabeling DNA restriction endonuclease fragments to high specific activity. Anal. Biochem. 132:6-13.

16. Leary, J.J., D.J. Brigati, and D.C. Ward. 1983. Rapid and sensitive colorometric method for visualizing biotin-labeled DNA probes hybridized to DNA or RNA immobilized on nitrocellulose: bioblots. Proc. Nat1. Acad. Sci., USA $80: 4045-4049$.

17. Schowalter, D.B., and S.S. Sommer. 1989. The generation of DNA and RNA probes with polymerase chain reaction. Anal. Biochem. 177:90-94.

18. Saiki, R.U., D.N. Gelfand, S. Stoffel, S.J. Scharf, R. Higuchi, G.T. Horn, M.B. Mullis, and H.A. Erlich. 1988. Primer-directed enzymatic amplification of DNA with a thermostable DNA polymerase Science 239:487-491

19. Chomczynski, P., and N. Sacchi. 1987. Single step method of RNA isolation by acid guanidium thiocyanate-phenol-chloroform extraction. Anal. Biochem. 162:156-159. 